\title{
Density, speed of sound and refractive index for the binary systems DBE + 1-hexene, or heptane, or cyclohexane, or 2, 2, 4 trimethyl-pentane, or toluene, or methyl-cyclohexane at $298.15 \mathrm{~K}$
}

\author{
C. Peral, A. Martínez-Terradillos, F. Aguilar, F.E.M. Alaoui, and E. Montero \\ Departamento de Ingeniería Electromecánica, Universidad de Burgos, Burgos, Spain
}

The increasing worldwide use of bio-fuels constitutes one of the measures considered to reduce greenhouse gas emissions. Bio-fuels also have an important part to play in promoting the security of energy supply, and promoting technological development and innovation. Dibutylether (DBE) is used as blending agent in reformulated gasoline and has been included in recent international regulations on the promotion of the use of energy from renewable sources for transport [1]. The DBE acts as non-polluting, high octane number blending agent. DBE could be also used as cetane enhancer in bio-diesel fuel, and can be obtained as an added valued additive to second generation bio-fuels [2].

DBE, having similar properties (e.g., vapour pressures) to hydrocarbons and the potential to increase the octane number and to decrease the emission of carbon monoxide, have become important additives for gasoline. The ethers increase the amount of oxygen in gasoline in order to reduce the $\mathrm{CO}$ content in the exhaust gas of automobiles. DBE, pure or mixed with alkanols or alkanes, has been recommended as a high octane blending agent for motor gasoline.

Experimental densities, speeds of sound and refractive indexes for the binary systems $\mathrm{DBE}+1$-hexene, or heptane, or cyclohexane, or 2,2,4 trimethyl-pentane, or toluene, or methyl-cyclohexane have been measured at $298.15 \mathrm{~K}$ and at atmospheric pressure. The excess molar volumes and the deviations in isentropic compressibility upon mixing have been correlated by the Redlich-Kister polynomial.

We acknowledge support for this research to the Ministerio de Ciencia e Innovación, Spain, Project ENE2009-14644-C02-02.

\section{References}

1. Directive 2009/28/EC of the European Parliament ad of the Council on the promotion of the use of energy from renewable sources
2. R. Kotrba, Ethanol Producer Magazine 2005 November 